\title{
As contribuições de Georg Lukács para a compreensão da categoria trabalho e os complexos sociais
}

\author{
Aline Laureano Machado \\ Universidade Estadual do Ceará ${ }^{1}$ \\ Jucilene Silva de Oliveira \\ Universidade Estadual do Cearáa
}

Resumo: O escopo do resumo consiste em analisar, de modo geral, as contribuições teóricas e filosóficas de Lukács para a compreensão do trabalho como categoria fundante do ser social, bem como analisar os complexos sociais da educação e da linguagem que surgiram e desenvolveram-se concomitantes ao trabalho. Nesse sentido, entende-se que esta pesquisa ergue-se mediante algumas indagações: quais as necessidades de compreensão a respeito dos complexos há pouco mencionados? Como o trabalho poderia ser parte fundante do desenvolvimento social desses complexos?.A pesquisa é de natureza teórico-bibliográfica, referenciadas em autores marxistas clássicos e contemporâneos, tendo o materialismo histórico dialético como método balizador.

Palavras-chave: Trabalho; Educação; Linguagem.

\section{Georgy Lukács contributions to understanding the work category and social complexes}

\begin{abstract}
The scope of the abstract is to analyze, in a general way, the theoretical and philosophical contributions of Lukács to the understanding of work as a founding category of social being, as well as to analyze the social complexes of education and language that emerged and developed concurrently with the work. In this sense, it is understood that this research arises through some questions: what are the needs for understanding about the complexes just mentioned? How could work be a fundamental part of the social development of these complexes? The research is theoreticalbibliographic in nature, referenced in classic and contemporary Marxist authors, using dialectical historical materialism as a guiding method.
\end{abstract}

Keywords: Work; Education; Language.

\footnotetext{
${ }^{1}$ Mestranda pelo Programa de Pós-Graduação em Educação pela Universidade Estadual do Ceará. Orcid: https://orcid.org/0000-0002-6670-9413. E-mail: alinemachado200@hotmail.com

2 Mestra em Educação Brasileira pelo Programa de Pós-Graduação em Educação pela Universidade Estadual do Ceará. Orcid: https://orcid.org/0000-0002-4431-783. E-mail: juscy.silva@,hotmail.com
}

Cadernos GPOSSHE On-line, Fortaleza, v. 5, n. 1, 2021

https://revistas.uece.br/index.php/CadernosdoGPOSSHE

DOI: $10.33241 /$ cadernosdogposshe.v5i1

ISSN: $2595-7880$ 


\section{INTRODUÇÃO}

O presente resumo tem como objetivo analisar a função da linguagem e da educação associados ao complexo do trabalho como categoria fundante do ser social à luz de Lukács.

Os complexos sociais contribuem para o processo de socialização e humanização entre os homens. A linguagem é um complexo existente entre todos os homens, caracterizando-se como um complexo universal que perpassa o trabalho, a educação e os demais complexos sociais. Lukács (2013, p. 225) afirma que a "linguagem é um autêntico complexo social dinâmico". O complexo da linguagem viabiliza a continuidade do ser social e desempenha um papel de portadora da continuidade a partir das práticas de oralidade tradicionais.

A educação, assim como a linguagem, possui também essa característica de ser portadora da continuidade do ser social. O complexo da educação destaca-se por ser um complexo que desenvolve a socialização entre os homens, é um complexo social a qual as gerações adultas transmitem conhecimentos, valores, culturas e tradições para as gerações jovens, isto é, esse tipo de educação tem uma particularidade de ser uma educação ampla que nunca estará finalizada durante o decorrer da existência humana. Lukács (2013, p. 178) esclarece que a essência da educação “[...] consiste em influenciar os homens no sentido de reagirem a novas alternativas de vida socialmente intencionado". A educação em seu sentido amplo tem por objetivo apresentar aos indivíduos uma realidade totalmente humana, ou seja, o próprio mundo dos homens. O processo formativo dos homens nunca se encerra, pois os homens mergulhados nas relações sociais entre si, vão-se educando e adquirindo cada vez mais conhecimento em uma realidade totalmente humana. $\mathrm{O}$ objetivo medular de nossa pesquisa consiste na fundamental ampliação do conhecimento sobre a fruição estética e o educar dos sentidos humanos com o fim de evidenciar qual " a função social da arte" na vida dos homens.

\section{METODOLOGIA}


Para a realização da discussão aqui apresentada, utilizou-se como metodologia a pesquisa bibliográfica. Ainda, a pesquisa está embasada em autores da perspectiva crítica que auxiliam na análise do resumo supracitado. Utilizou-se o referencial teórico do materialismo histórico e dialético, em Marx, e a ontologia de Gyorge Lukács a fim de que se compreenda a categoria trabalho imbricada nos complexos sociais da linguagem e da educação.

\section{RESULTADOS E DISCUSSÕES}

Para compreender a finalidade da linguagem e da educação na vida dos homens, parte-se do fundamento da ontologia lukacsiana como referencial teórico esclarecedor da importância do desenvolvimento do trabalho na constituição do ser social. $\mathrm{O}$ acúmulo histórico das objetivações do trabalho, tanto materiais quanto não materiais, engendrou novas necessidades e novas possibilidades ao homem e à sociedade.

Por meio do trabalho, o homem é sujeito criador de sua própria história, capaz de transformar conscientemente a natureza e autoconstruir-se. Para Lukács (1978, p. 04), “A essência do trabalho consiste precisamente em ir além dessa fixação dos seres vivos na competição biológica com seu mundo ambiente". O ser humano foi desenvolvendo uma consciência daquilo que era externo a ele, o mundo, e foi dando finalidade a esse mundo, criando uma segunda natureza por meio de seu trabalho: o ser social. Há aqui, entretanto, a relação dialética indispensável entre produção e reprodução: o homem produz-se, mas, ao mesmo tempo, para tal, ele reproduz-se.

Dentre os complexos sociais que sustentam a reprodução do homem está a educação. A educação nasce como um complexo social da necessidade de o homem transmitir aos demais membros de sua espécie os conhecimentos, as habilidades, as técnicas, os valores etc. e a humanidade historicamente produzida pelo conjunto dos homens. A história nada mais é do que o resultado da relação entre a consciência humana e o mundo objetivo. Sobre o processo de trabalho, vale ressaltar que, na terminologia de Lukács, a projeção do objeto na consciência é nominada de prévia-ideação e a prática da ideia, de objetivação. A primeira é sempre uma resposta a um determinado carecimento. A segunda, apesar de dar vida a um novo objeto, não despreza a natureza, mas transforma-a de acordo com os interesses dos 
homens. A linguagem, não pode ser separada do processo de autoconstrução do homem enquanto ser social, gênero. Tal concepção deve ser compreendida em sua integralidade para que se possa perceber que a linguagem não é reflexo idealizado, desvinculado da realidade, já que ela é produto da própria atividade humana.

É uma tarefa militante não se dar ao direito de pensar educação, trabalho e linguagem apartados do ser social em sua integralidade, pois estes complexos possuem sua legalidade própria, autonomia relativa e dependência ontológica porque desenvolve os sentidos humanos para, em contato com obras elevadas, cada indivíduo singular alçar-se gênero humano e, portanto, adquirir conhecimento sobre o mundo e seu papel revolucionário nele, como membro da classe que, por sua posição, deve transformá-la.

\section{CONSIDERAÇÕES FINAIS}

Pelo exposto até aqui, em uma perspectiva marxista lukacsiana, o complexo da linguagem associado ao desenvolvimento do trabalho seguramente constituem em suas relações seres socialmente enriquecidos, capazes de fazer e de fruir educação. A presente análise desenvolvida, de modo geral, possibilitou-nos uma compreensão em torno da relevância da centralidade da categoria do trabalho na construção de um mundo dos homens humanizado no qual os homens produzem ininterruptamente a sua produção material. Todavia, os homens não se esgotaram em apenas transformar a natureza. Tal como Marx (2011, p. 327) "agindo sobre a natureza externa e modificando-a por meio desse movimento, ele modifica, ao mesmo tempo, a sua própria natureza”. Desse modo, com o surgimento dos complexos sociais na sociabilidade humana permitiram uma transformação na própria condição do ser social que passa a ter características mais sociais que possibilitaram aos homens novos conhecimento sobre a natureza e de si mesmo.

Acredita-se que a educação associada ao desenvolvimento do trabalho e da linguagem, possibilita a plena superação do homem enquanto ser social imerso em um cotidiano, sendo dessa forma, partes indispensáveis para gerar uma sociedade emancipada.

\section{Referências}

Cadernos GPOSSHE On-line, Fortaleza, v. 5, n. 1, 2021 
LUKÁCS, Giörgy. Para uma Ontologia do Ser Social II /György Lukács : tradução de Nélio Schnneider, Ivo Tonet e Ronaldo Vielmi Fontes. 1. ed. São Paulo: Boitempo editorial, 2013.

LUKÁCS, György. As bases Ontológicas do Pensamento e da Atividade do Homem. http://www.gestaoescolar.diaadia.pr.gov.br/arquivos/File/sem pedagogica/fev 2009/bas es ontologicas pensamento atividade homem lukacs.pdf.

MARX, Karl. O capital: Crítica da economia política. Livro I. O processo de produção do capital. Tradução de Rubens Endele. São Paulo: Boitempo, 2011.

Trabalho oriundo do I Seminário do GPOSSHE - Educação do campo e Pedagogia histórico-crítica em contexto de crise e pandemia 